\title{
PERANAN PENJADWALAN OPERASI TERHADAP PENINGKATAN EFESIENSI PADA PEMBANGUNAN JEMBATAN RUMPIANG DI PT VIRAMA KARYA
}

\author{
Dewi Taurusyanti \\ Dosen Tetap Fakultas Ekonomi \\ Universitas Pakuan \\ Mico Afriansyah \\ Mahasiswa Fakultas Ekonomi \\ Universitas Pakuan
}

\begin{abstract}
Basically when built the company we all have a hope that the company will develop someday and get the target, such as maximum profit or make a product or service with the use of maximum resources.

Schedulling is an allocation decision of resources made available by facilities decision an aggregate planning. Schedulling is an important part of activity in the company, because it refers to the process of preparing a time target for all production operating activities including set up and after preparation time in executing a production order.

The research use descriptive explorative method by case study, and the type of the research technique is statistic quantitative using PERT-CPM method. The analysis unit of this research is the construction unit of the company.

PERT - CPM analysis allows uncertainty in the activity times when activity times are difficult to predict, PERT can provide estimates the impact of uncertainty on the project's completion time. However, reason given in the analysis results are only approximation, because there are other factors contibuted in bridge project.

Analysis method with CPM, can useful for the company to know about the efficiency time and cost from operation schedulle. From the analysis result can be described that normal time is 320 weeks can be reduced to 224 weeks resulting in 70\% of throughput efficiency.
\end{abstract}

Key Words; Operations Management, Project Management, Operation Schedulling, CPM Method, Act of Determining Time and Raising Efficiency

\section{Pendahuluan}

Salah satu faktor penting dalam keberhasilan pengembangan penerapan keberhasilan dalam pelaksanaan proyek untuk selesai tepat pada waktunya adalah tujuan pokok dan utama, baik bagi pihak kontraktor dan pemilik. Penjadwalan memiliki pengaruh yang penting dalam mengefesiensikan waktu dan biaya. Merupakan pengaturan aktifitas-aktifitas melalui koordinasi waktu dan biaya dalam menyelesaikan keseluruhan pekerjaan, pengalokasian 
sumber daya dan aktifitas pada masing-masing, agar keseluruhaan pekerjaan dapat diselesaikan dengan waktu dan biaya efesien.

CPM adalah suatu aktivitas dalam sebuah proyek dengan mengurut suatu aktivitas sehingga mempersempit waktu kegiatan proyek secara keseluruhan. Jika suatu aktivitas didalam suatu lintasan kristis ditunda maka mengakibatkan seluruh kegiatan proyek akan tertunda.

Lintasan kritis adalah lintasan yang menentukan penyelesaian proyek secara keseluruhan. Cara mencari lintasan kritis, antara lain dengan mengunakan teknik evaluasi dan pengulasan proyek, metode jalur kritis.

PT VIRAMA KARYA adalah salah satu perusahaan yang bergerak dalam bidang konsultan dan kontraktor. Perusahaan ini membuat dari desain hingga proses penjadwalan operasi pembangunan seperti gedung, jembatan, dan lain-lain. PT VIRAMA KARYA mempunyai masalah seperti dalam proyek pembangunan sebuah Jembatan perlu adanya penanganan manajemen penjadwalan kerja yang baik, karena itu perlu ditangani dengan perhitungan yang cermat dan teliti. Dimana pembangunan jembatan ini mengalami keterlambatan yang seharusnya selesai tahun 2004 namun baru selesai tahun 2008. Akan dibahas tentang waktu penjadwalan operasi proyek dimana belum optimal. Metode PERTCPM, digunakan untuk mengetahui pekerjaan mana saja yang harus dikerjakan terlebih dahulu atau tidak boleh ditunda pelaksanaannya (kegiatan kritis), agar jadwal operasi teroptimalisasi dengan baik, sehingga keterlambatan dapat dikendalikan dan dihindari. Metode PERT dan CPM hanya merupakan suatu alat perencanaan dan pengawasan, karena alat ini juga memerlukan suatu cara atau sistem pendukung, sehingga akan didapatkan suatu hasil yang optimal.

Oleh karena itu, Tujuan penelitian adalah sebagai berikut: 1) Menganalisis hasil penjadwalan operasi PT. Virama Karya untuk waktu penyelesaian agar optimal dengan menggunakan PERT-CPM; 2) Menganalisis penjadwalan operasi terhadap peningkatan efesiensi waktu dengan membandingkan hasil perhitungan waktu dalam menentukan lintasan kritis dengan PERT CPM, dan Microsoft Excel dengan hasil analisis kontraktor

\section{Metode Penelitian}

Metode yang digunakan dalam penelitian ini adalah Statistik kuantitatif terhadap Pembangunan Jembatan Proyek pada PT Virama Karya dengan menggunakan metode CPM. Adapun langkah-langkahnya adalah sebagai berikut : 


\section{a. Perhitungan Maju}

Dalam perhitungan maju, ada tiga langkah yang harus dilakukan, yaitu:

1. Saat tercepat terjadinya initial event ditentukan pada hari ke nol sehingga untuk initial event berlaku $\mathrm{TE}=0$.

2. Kalau initial event terjadi pada hari ke-nol

$$
\begin{aligned}
& E S(i, j)=T E(j)=0 \\
& E F(i, j)=E S(i . j)+t(i, j) \\
& \text { maka, } \quad E F(i, j)=T E(i, j)+t(i, j)
\end{aligned}
$$

3. Event yang menggabungkan beberapa aktivitas.

Sebuah event hanya dapat terjadi jika aktivitas aktivitas yang mendahuluinya telah diselesaikan.

$\mathrm{TE}(\mathrm{j})=\max (\mathrm{EF}(\mathrm{i} 1, \mathrm{j}), \operatorname{Ef}(\mathrm{i} 2, \mathrm{j}), \ldots \mathrm{EF}(\mathrm{in}, \mathrm{j})$

\section{b. Perhitungan Mundur}

Seperti halnya pada perhitungan maju, pada perhitungan mundur ini pun terdapat tiga langkah, yaitu.

1. Pada terminal event berlaku $\mathrm{TL}=\mathrm{TE}$.

2. Saat paling lambat untuk memulai suatu aktivitas sama dengan saat paling lambat untuk menyelesaikan aktivitas itu dikurangi dengan duration aktivitas tersebut.

\section{3. $\mathbf{L S}=\mathbf{L F}-\mathbf{t}$}

$\mathrm{LF}(\mathrm{i}, \mathrm{j})=\mathrm{TL}$, dimana $\mathrm{TL}=\mathrm{TE}$

maka, $\operatorname{LS}(\mathrm{i}, \mathrm{j})=\mathrm{TL}(\mathrm{j})-\mathrm{t}(\mathrm{i}, \mathrm{j})$

4. Event yang "mengeluarkan” beberapa aktivitas (burst event).

$\mathrm{TL}(\mathrm{i})=\min (\operatorname{LS}(\mathrm{i}, \mathrm{j} 1), \operatorname{Ls}(\mathrm{i}, \mathrm{j} 2, \ldots, \mathrm{LS}(\mathrm{i}, \mathrm{jn}))$

\section{c. Perhitungan Kelonggaran Waktu (Float atau Slack)}

Untuk menghitung total float dan free float digunakan rumus sebagai berikut,

$$
\begin{aligned}
& S(i, j)=T E(i)-T L(j)-(t(i, j)) \\
& S F(i, j)=T E(i)-T L(j)-(t(i j))
\end{aligned}
$$

Keterangan :

$\mathrm{S}(\mathrm{i}, \mathrm{j}) \quad=$ Total float dari kejadian i menuju ke $\mathrm{j}$.

$\mathrm{SF}(\mathrm{i}, \mathrm{j}) \quad=$ Free float dari kejadian i menuju ke j.

\section{d. Lintasan Kristis dengan Melakukan Penjadwalan}

Metode lintasan kristis (CPM) dalam penjadwalan proyek menggunakan keseimbangan waktu dan biaya bukan waktu probabilitas, serta mengunakan fungsi waktu dan biaya 
tersebut. Kegiatan dapat diselesaikan dalam waktu secara proporsional, lebih sedikit waktu jika lebih banyak biaya yang dikeluarkan. Untuk mengungkap hubungan waktu dan biaya ada empat angka dipasang untuk kegiatan: waktu normal, biaya normal, waktu pintas, biaya pintas. seperti dapat dilihat dalam Gambar ini

\section{Biaya Pintas

\begin{tabular}{|c|c|}
\hline & Biaya \\
\hline 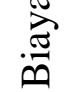 & Normal \\
\hline
\end{tabular}

Waktu Pintas

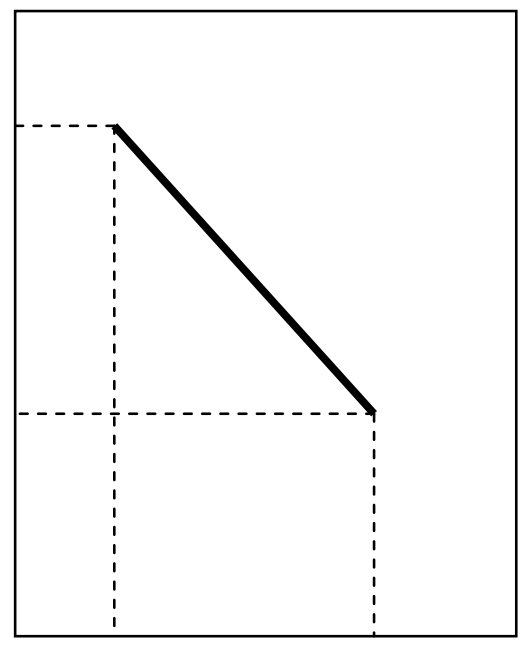

\section{Waktu Pintas Biaya Normal}

Waktu Pintas
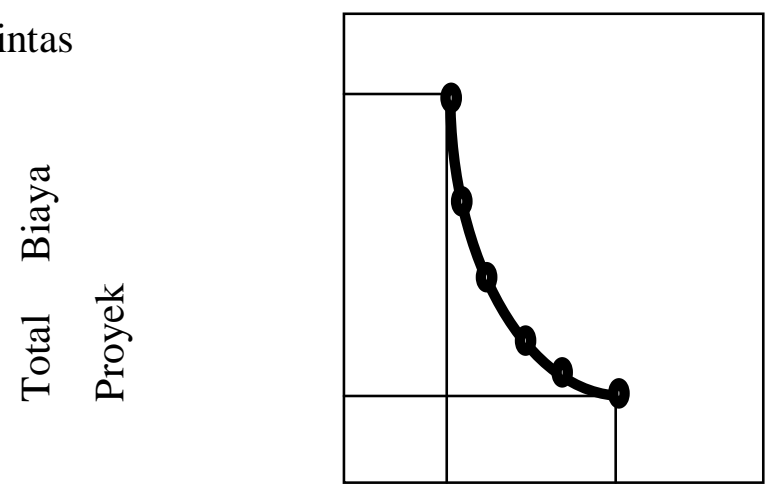

Biaya Normal

$$
\text { Waktu Pintas Waktu Normal }
$$

Total Waktu Proyek (Penyelesaian)

Gambar 4. Trade Off waktu dan biaya CPM

\section{Hasil dan Pembahasan}

\subsection{Penjadwalan Operasi}


Proses metode penjadwalan pada PT. virama Karya melewati beberapa tahap, dari mulai tahap persiapan, tahap studi dan analisa data, tahap premiminary design, tahap detail design, tahap laporan teknik dan dokumen. Metode Penjadwalan dan urutan kegiatan dilihat dari Jaringan, waktu, dan biaya antara lain sebagai berikut:

\section{Tahap persiapan}

Kegiatan A adalah pengumpulan data sekunder dengan waktu kegiatan selama 2 minggu. Kegiatan B adalah persiapan kantor dan peralatan dengan waktu kegiatan selama 2 minggu. Kegiatan C adalah mobilisasi personil dengan waktu kegiatan selama 3 minggu. Kegiatan D adalah koordinasi rencana kerja dan pembagian tugas dengan waktu selama 5 minggu. Dengan memakan biaya sebesar Rp. 3.175.000.000.

\section{Tahap studi $\&$ analisa data}

Kegiatan A adalah survei pendahuluan dengan waktu kegiatan selama 2 minggu. Kegiatan B adalah Survei Tofografi \& bathimetri dengan waktu kegiatan selama 2 minggu. Kegiatan $\mathrm{C}$ adalah Survei Hidrologi dengan waktu kegiatan selama 4 minggu. Kegiatan D adalah Studi Geologi dengan waktu selama 4 minggu. Kegiatan E adalah Penyelidikan Geoteknik dengan waktu selama 10 minggu. Dengan memakan biaya sebesar Rp. 1.981.130.440.

\section{Tahap Premiminary Design}

Kegiatan A adalah Studi Perencanaan Terdahulu, Konsep dan Kriteria Desain Standar dengan waktu kegiatan selama 2 minggu. Kegiatan B adalah Penetapan Layout Jembatan dengan waktu kegiatan selama 4 minggu. Kegiatan C adalah Penetapan Layout Drainase dengan waktu kegiatan selama 2 minggu. Kegiatan D adalah Penetapan Bangunan Atas Jembatan (Superstructure) Untuk Bentang Utama dengan waktu selama 2 minggu. Kegiatan E adalah Penetapan Bangunan Bawah Jembatan (Substructure) Untuk Bentang Utama dengan waktu selama 2 minggu. Kegiatan F adalah Penetapan Bangunan Atas Jembatan (Superstucture) Untuk Bentang Pendek dengan waktu kegiatan selama 2 minggu. Kegiatan G adalah Penetapan Bangunan Bawah Jembatan (Substructure) Untuk an waktu kegiatan selama 2 minggu. Kegiatan H adalah Penetuan Fasilitas Jalan (PJU dan Drainase) dengan waktu kegiatan selama 4 minggu. Kegiatan I adalah Pengambaran (Plan, Profile, Cross Section dan Tipikal) dengan waktu selama 6 minggu. Dengan memakan biaya sebesar Rp. 89.442.546.853. 


\section{Tahap Detail Design}

Kegiatan A adalah Plan dan Profile Jalan dengan waktu kegiatan selama 16 minggu, serta memakan biaya sebesar Rp. 25.692.850. Kegiatan B adalah Perencanaan Drainase dengan waktu kegiatan selama 12 minggu, serta memakan biaya sebesar Rp. 452.236.300. Kegiatan C adalah Detail Desain Jembatan Utama ( Bentang Utama ) dengan waktu kegiatan selama 55 minggu, serta memakan biaya sebesar Rp. 48.705.200.000. Kegiatan D adalah Detail Desain Jembatan Pendekat ( Bentang Pendek) dengan waktu selama 49 minggu, serta memakan biaya sebesar Rp. 51.081.500.000. Kegiatan E adalah Detail Desain Fasilitas Jalan (PJU dan Drainase) dengan waktu selama 12 minggu, serta memakan biaya sebesar Rp. 452.236.300. Kegiatan F adalah Penggambaran Detail ( Plan, Profile, Cross Section dan Bentang Utama \& Pendek ) dengan waktu kegiatan selama 19 minggu, serta memakan biaya sebesar Rp. 25.692.850. Kegiatan G adalah Metode Konstruksi dengan waktu kegiatan selama 12 minggu, serta memakan biaya sebesar Rp. 122.056.634. Kegiatan H Manajemen Lalu Lintas dengan waktu kegiatan selama 8 minggu, serta memakan biaya sebesar Rp. 122.056.634. Kegiatan I adalah Penyiapan Laporan Teknik dengan waktu selama 16 minggu, serta memakan biaya sebesar Rp. 122.056.634. Kegiatan J adalah Penyiapan Bill of Quantity dengan waktu selama 19 minggu, serta memakan biaya sebesar Rp. 122.056.634. Kegiatan K adalah Penyiapan Dokumen Pelelangan dengan waktu kegiatan selama 20 minggu, serta memakan biaya sebesar Rp. 122.056.634.

\section{Laporan Teknik dan Dokumen}

Kegiatan A adalah Penyerahan Market dengan waktu kegiatan selama 2 minggu, serta memakan biaya sebesar Rp. 122.056.634. Kegiatan B adalah Laporan Pendahuluandengan waktu kegiatan selama 2 minggu, serta memakan biaya sebesar Rp. 122.056.634. Kegiatan C adalah Detail Laporan Kemajuan Pekerjaan dengan waktu kegiatan selama 2 minggu, serta memakan biaya sebesar Rp. 122.056.634. Kegiatan D adalah Detail Laporan Survei dengan waktu selama 2 minggu, serta memakan biaya sebesar Rp. 122.056.634. Kegiatan E adalah Konsep Laporan Akhir dengan waktu selama 2 minggu, serta memakan biaya sebesar Rp. 122.056.634. Kegiatan F adalah Laporan Akhir dan Dokumen Tender dengan waktu kegiatan selama 2 minggu, serta memakan biaya sebesar Rp. 122.056.634. 


\subsection{Hasil Metode Analisis}

Peranan penjadwalan operasi pada PT. Virama Karya dengan menggunakan metode analisis dimulai dari penggambaran jaringan, menghitung dengan perhitungan maju, perhitungan mundur, kelonggaran waktu.

Dari tabel biaya diatas didapatlah grafik trade off waktu dan biaya pada

Penjadwalan PT. Virama Karya antara lain sebagai berikut

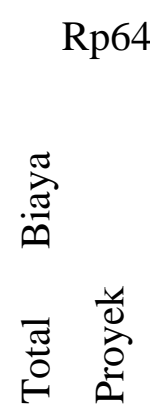

Rp366.667.792,00

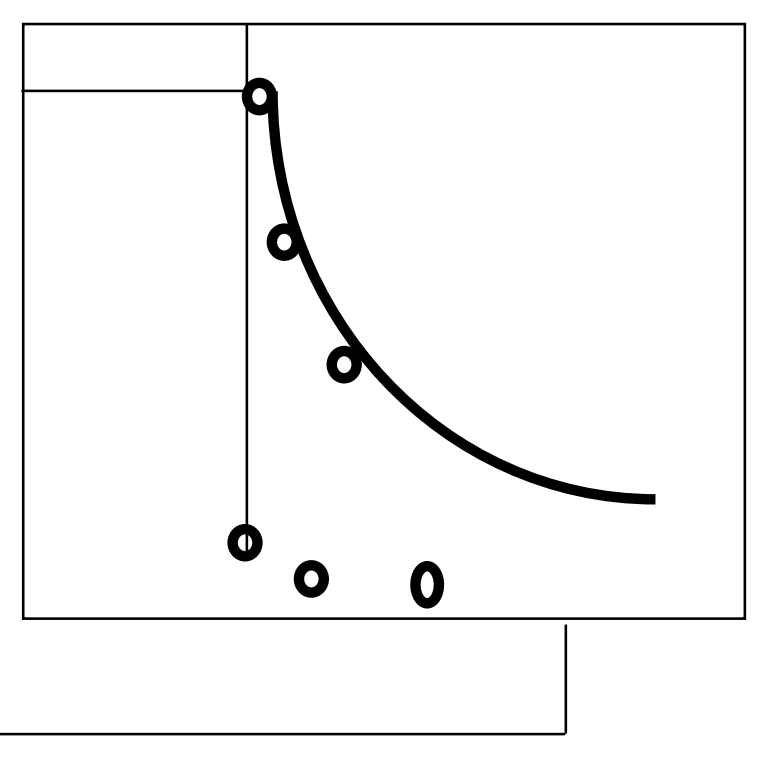

224

320

Total Waktu Proyek (Penyelesaian)

Keterangan:

Total Waktu Normal $=320$

Total Waktu Pintas $=224$

Total Biaya Normal $=$ Rp366.667.792,00

Total Biaya Pintas $\quad=$ Rp643.521.935,00

Sedangkan untuk mengukur efesiensi dengan mengunakan rasio Throughput Effeciency atau TE dengan rumus sebagai berikut:

$$
\begin{aligned}
\mathrm{TE} & =\frac{\text { total waktu kerja yang digunakan }}{\text { total waktu operasi }} \times 100 \% \\
& =\frac{224}{320} \times 100 \%=70 \%
\end{aligned}
$$




\section{Keterangan:}

( TE ) Efesiensi jumlah yang didapat sebesar $70 \%$

Total waktu kerja yang digunakan jam-mesin (machine hours) atau jam-orang yang sebenarnya adalah 224 untuk menyelesaikan pekerjaan tersebut

Total waktu operasi atau total waktu tenaga kerja sebenarnya adalah 320 untuk menyelesaiakan pekerjaan tersebut.

\section{Kesimpulan}

Perusahaan menetapkan rangkaian proses bisnis perusahaan yang diidentifikasi dan ditetapkan kriteriannya di dalam dokumen Sistem Mutu Perusahaan. Sistem Manajemen Mutu tesebut harus ditetapkan, didokumentasikan, diterapkan, dipelihara dan secara terus menerus ditingkatkan keefektifannya untuk memberikan konstribusi manfaat secara luas bagi perusahaan. Dari hasil penelitian dapat disimpulkan bahwa:

1. Setelah dianalisa didapatlah bahwa penjadwalan yang dilakukan perusahaan dengan metode bagan chart belum optimal. Penjadwalan ini lebih dilakukan secara manual dengan mengikuti atau menguruti kegiatan-kegiatan sebelumnya ataupun sesudahnya, sesuai yang diingikan. Namun memiliki kejelasan pada saat waktu dan biaya karena lebih mudah dibaca secara berurutan.

2. Dengan Menggunakan CPM (critical path method) kita bisa membuat penjadwalan yang lebih efesien, karena bisa mengefesienkan waktu dan biaya. Waktu bisa lebih efesien dengan cara melakukan perhitungan maju dengan mencari waktu tertinggi dilanjutkan dengan perhitungan mundur dengan mencari waktu terendah setelah itu mencari slack atau kelonggaran waktu dimana slack ini digunakan untuk mengetahui kegiatan mana yang harus didahulukan atau biasa disebut juga dengan lintasan Kritis.

\section{Daftar Pustaka}

Aulia Ishak.2010.Manajemen Operasi. Yogyakarta : Graha Ilmu.

Chaser Aquilino, Jacobs.2001. Operations Management. Jakarta : Salemba.

Dimyati,T.T. dan A Dimyati,2004 Operations Research Model-Model Pengambilan Keputusan. Bandung: Sinar Baru Algesindo.

Lauden, K.C. dan J.P. Lauden.2005 Sistem iNformasi manajemen mengelola Perusahaan Digital Edisi 8 Yogyakarta: Andi. 
Schroeder, et al. 2011. Operations Management (Fifth Edition), New York: The McGrawHill Companies. Inc.

T. Hani Handoko. 2008. Dasar-dasar manajemen Produksi dan Operasi. Yogyakarta: BPFE. Wiryana, Made dan Cristianto.2001. manajemen Proyek Berbasis Internet, jakarta PT. Elex Komputindo kelompok gramedia.

Wiwoho,A. 2007. Penjadwalan kerja Menggunakan Metode Lintasan Kritis dengan Keterbatasan. $\quad$ http://digilib.math.itb.ac.id/go.php?id=jbptitbmath-gdl-s1-2006alvaniwiwo-1206

Wulfram,I. Ervianto.2005.manajemen Proyek Konstruksi (Edisi Revisi), Yogyakarta: Andi. 